\title{
Correlates of facility-based delivery among women of reproductive age from the Digo community residing in Kwale, Kenya
}

Vernon Mochache ${ }^{1,2^{*}} \mathbb{D}$, Amyn Lakhani ${ }^{3}$, Hajara El-Busaidy ${ }^{4}$, Marleen Temmerman ${ }^{1,2,3}$ and Peter Gichangi ${ }^{1,2,5}$

\begin{abstract}
Objective: This study sought to describe factors associated with facility-based delivery among women of reproductive age in Kwale County, Kenya.

Results: Between March and December 2015, 745 women from 15 villages were interviewed through a crosssectional household survey. Respondents were selected using stratified, systematic sampling and completed a sexual and reproductive health questionnaire. Of 632 (85\%) women who had a previous birth, 619 (98\%) reported antenatal care attendance. Of these, 491 (79\%) subsequently had a facility-based delivery. Factors associated with increased likelihood of facility delivery included respondent's education (odds ratio, $\mathrm{OR}=2.0,95 \%$ confidence interval, $\mathrm{Cl}$ 1.2-3.2, $\mathrm{P}=0.004)$, ideal antenatal care attendance $(\mathrm{OR}=2.3,95 \% \mathrm{Cl} 1.4-3.7, \mathrm{P}=0.001)$ and pregnancy intention $(\mathrm{OR}=1.5$, $95 \% \mathrm{Cl} 1.0-2.2, \mathrm{P}=0.040)$. Being in a polygamous relationship $(\mathrm{OR}=0.6,95 \% \mathrm{Cl} 0.3-0.9, \mathrm{P}=0.024)$ and having a husband $\geq 40$ years $(\mathrm{OR}=0.5,95 \% \mathrm{Cl} 0.3-0.9, \mathrm{P}=0.013)$ were associated with reduced likelihood of facility delivery. Respondent's education $(\mathrm{aOR}=1.9,95 \% \mathrm{Cl} 1.1-3.3, \mathrm{P}=0.030)$ as well as ideal $\mathrm{ANC}$ attendance $(\mathrm{aOR}=2.0,95 \% \mathrm{Cl}$ $1.0-3.8, P=0.040$ ) remained significantly associated with facility delivery in multivariate analyses.
\end{abstract}

Keywords: Correlates, Facility-based delivery, Women of reproductive age, Digo, Kwale, Kenya

\section{Introduction}

While obstetric delivery in a health facility has been associated with favourable maternal and neonatal outcomes, rates of facility-based delivery in the developing world remain unexpectedly low $[1,2]$. This is attributed to various factors including the influence of sociocultural context, low perception of risks associated with pregnancy and childbirth, fear of discrimination during delivery as well as barriers associated with physical distance to a health facility and costs associated with delivery [3].

Two European Commission-funded projects seeking to improve uptake and utilization of maternal and child health $(\mathrm{MCH})$ services, especially facility-based delivery

\footnotetext{
*Correspondence: vmochache@gmail.com

1 International Centre for Reproductive Health, P.O. Box 91109-80103, Mombasa, Kenya

Full list of author information is available at the end of the article
}

and contraception, were implemented in Kwale county, Kenya. The Missed Opportunities in Maternal and Infant (MOMI) health project leveraged missed opportunities in the postpartum period using facility and communitybased interventions [4]. The Mama na Mtoto (MNM) II project aimed to create demand for $\mathrm{MCH}$ services by enhancing community structures and meaningfully involving target communities [5].

Previous findings from these studies have shown high levels of contraceptive utilization among women of reproductive age (WRA) in this setting. This was associated with educational attainment, parity, antenatal (ANC) attendance at last delivery as well as intention to delay or stop future births [6]. Additionally, it was found that lay community health volunteers were instrumental in building demand for $\mathrm{MCH}$ services by acting as a 
bridge between the health system and surrounding communities [7].

The present study sought to further build on these findings by describing factors associated with facility-based delivery. As previously noted, while high rates of ANC attendance have been reported in this setting, the proportion of those pregnancies that are ultimately delivered at home still remains high $[8,9]$. Findings from this study will inform priorities for better $\mathrm{MCH}$ programming and contribute to improved uptake and utilization of skilled assistance at birth.

\section{Main text}

\section{Study design}

Data for this study were collected through a cross-sectional household survey conducted in Kwale between March and December 2015. The methods have been comprehensively described previously [6]. Briefly, a structured sexual and reproductive health (SRH) household questionnaire (see Additional file 1) was administered to women between 18 and 45 years. A sample size of $\sim 350$ respondents was estimated based on an anticipated $50 \%$ frequency of facility-based deliveries in this setting, a sample design effect of 2.5, Z-statistic of 1.96 for a $95 \%$ confidence level in the estimation, $10 \%$ nonresponse rate, and a $2.5 \%$ margin of error. Stratified, systematic random sampling was used to select respondents. Every qualifying female respondent per household was included in the study unless they failed to provide written informed consent or were not resident in the village for more than 6 months.

\section{Data management and statistical analyses}

Data were entered into a Microsoft Access (Microsoft Inc. Seattle, WA, USA) spreadsheet and migrated to Stata version 12 (StataCorp Inc., College Station, TX, USA) for statistical analyses. Demographic characteristics were summarized as counts $(\mathrm{N}) /$ percentages (\%) for categorical data and median (IQR) for continuous data and compared using Pearson's Chi squared test (categorical) and Wilcoxon rank-sum test (continuous).

The outcome of interest was self-reported delivery at a health facility among women reporting a previous birth. Odds of facility-based delivery were calculated among women with each characteristic of interest versus the reference group using multivariate logistic regression models with adjusted Odds Ratios (ORs) and 95\% confidence intervals (CIs) being reported. All statistical tests were evaluated using a 2 -sided $\alpha$-value of 0.05 .

\section{Ethical consideration}

Ethical approval for the study was obtained from the Research Ethics Committee of the Aga Khan University,
Nairobi (2014/REC-51) and the Ethics Review Committee of the University of Nairobi and Kenyatta National Hospital (P502/08/2014). A research permit from the National Commission for Science, Technology and Innovation (\#4703) was also obtained to facilitate the conduct of research activities in the community. All participants provided written informed consent.

\section{Results}

Between March and December 2015, a total of 745 female respondents were interviewed in 15 villages of Matuga sub-county, Kwale. Their median (IQR) age was 29 (23$37)$. Five hundred and sixty-eight $(76 \%)$ were currently in a marital union with the median (IQR) age of their husbands/partners being 39 (30-46). Further, 646 (87\%) women reported that they had ever attended school with the median (IQR) years of education being 8 (7-11). The median (IQR) ages at sexual debut and marriage were 18 (16-20) and 20 (18-23), respectively (Table 1 ).

Six hundred and thirty-two (85\%) respondents reported that they had ever given birth with the median (IQR) number of total births reported being 4 (2-5). Of these, 619 (98\%) had attended ANC during their last pregnancy. The median (IQR) duration of pregnancy at the time of attending the first ANC visit was 5 (4-6) months while the median (IQR) number of ANC visits attended was 4 (3-5). Further, 75 (10\%) women were currently pregnant at the time of the interview, with a median (IQR) pregnancy duration of $6(4-7)$ months. Of these, 60 (81\%) reported having ever attended ANC.

Among women who reported a previous birth, 493 (78\%) had delivered in a health facility during their last pregnancy, 107 (17\%) had delivered in their own home

Table 1 Demographic characteristics of household survey respondents $(n=745)$

\begin{tabular}{lc}
\hline Characteristic & N (\%)/median (IQR) \\
\hline Respondent's age & $29(23-37)$ \\
Husband/partner's age & $39(30-46)$ \\
Age at sexual debut & $18(16-20)$ \\
Age at marriage/union & $20(18-23)$ \\
Marital status & \\
Currently married & $426(57 \%)$ \\
Currently living as if married & $142(19 \%)$ \\
Currently not in a union & $177(24 \%)$ \\
Ever attended school & $646(87 \%)$ \\
Years of education & $8(7-11)$ \\
Ever given birth & $632(85 \%)$ \\
Total number of births & $4(2-5)$ \\
Currently pregnant & $75(10 \%)$ \\
Duration (months) of current pregnancy & $6(4-7)$ \\
\hline
\end{tabular}


while $32(5 \%)$ had delivered in someone else's home. This pattern was replicated among those who had attended ANC during their last pregnancy with 483 (78\%), 99 $(16 \%)$ and 31 (5\%) women having delivered in a health facility, in their own home and in another person's home, respectively. Among 13 women who had not attended ANC during their last pregnancy, only 8 (60\%) had delivered in a health facility (Fig. 1).

In univariate analysis, factors associated with delivery in a health facility included respondent's education $(\mathrm{OR}=2.0,95 \% \mathrm{CI} 1.2-3.2, \mathrm{P}=0.004)$, ideal ANC attendance $(\mathrm{OR}=2.3,95 \% \mathrm{CI} 1.4-3.7, \mathrm{P}=0.001)$ (defined as having attended $\geq 4$ ANC visits, having received information on pregnancy danger signs, having received $\geq 3$ tetanus toxoid vaccinations, having received anti-malarial, anti-helminthic and hematinic supplementation), as well as pregnancy intention $(\mathrm{OR}=1.5,95 \%$ CI $1.0-2.2$, $\mathrm{P}=0.040)$. Being in a polygamous relationship $(\mathrm{OR}=0.6$, $95 \%$ CI $0.3-0.9, \mathrm{P}=0.024$ ) as well as having a husband/ partner who was $\geq 40$ years $(\mathrm{OR}=0.5,95 \%$ CI $0.3-0.9$, $\mathrm{P}=0.013)$ were associated with reduced likelihood of a facility-based delivery.
When adjusted for age, education, marital status, ideal ANC attendance, being in a polygamous relationship and pregnancy intention; respondent's education $(\mathrm{aOR}=1.9$, 95\% CI 1.1-3.3, $\mathrm{P}=0.030$ ), and ideal ANC attendance $(\mathrm{aOR}=2.0,95 \% \mathrm{CI}: 1.0-3.8, \mathrm{P}=0.040)$ remained significantly associated with facility-based delivery (Table 2).

\section{Discussion}

This cross-sectional survey of WRA from the Digo community resident in Kwale County, Kenya revealed a high proportion of facility-based delivery at recent birth. Women were more likely to have delivered in a health facility if they had ever attended school and if they had intended to get pregnant. Women who reported receiving ideal ANC services during their previous pregnancy were also more likely to deliver in a facility. Conversely, women were less likely to deliver in a health facility if they were in a polygamous relationship and if their husband/partner was older.

Our findings are consistent with key characteristic of pregnancy and childbirth in the developing world where the proportion of facility-based deliveries lags

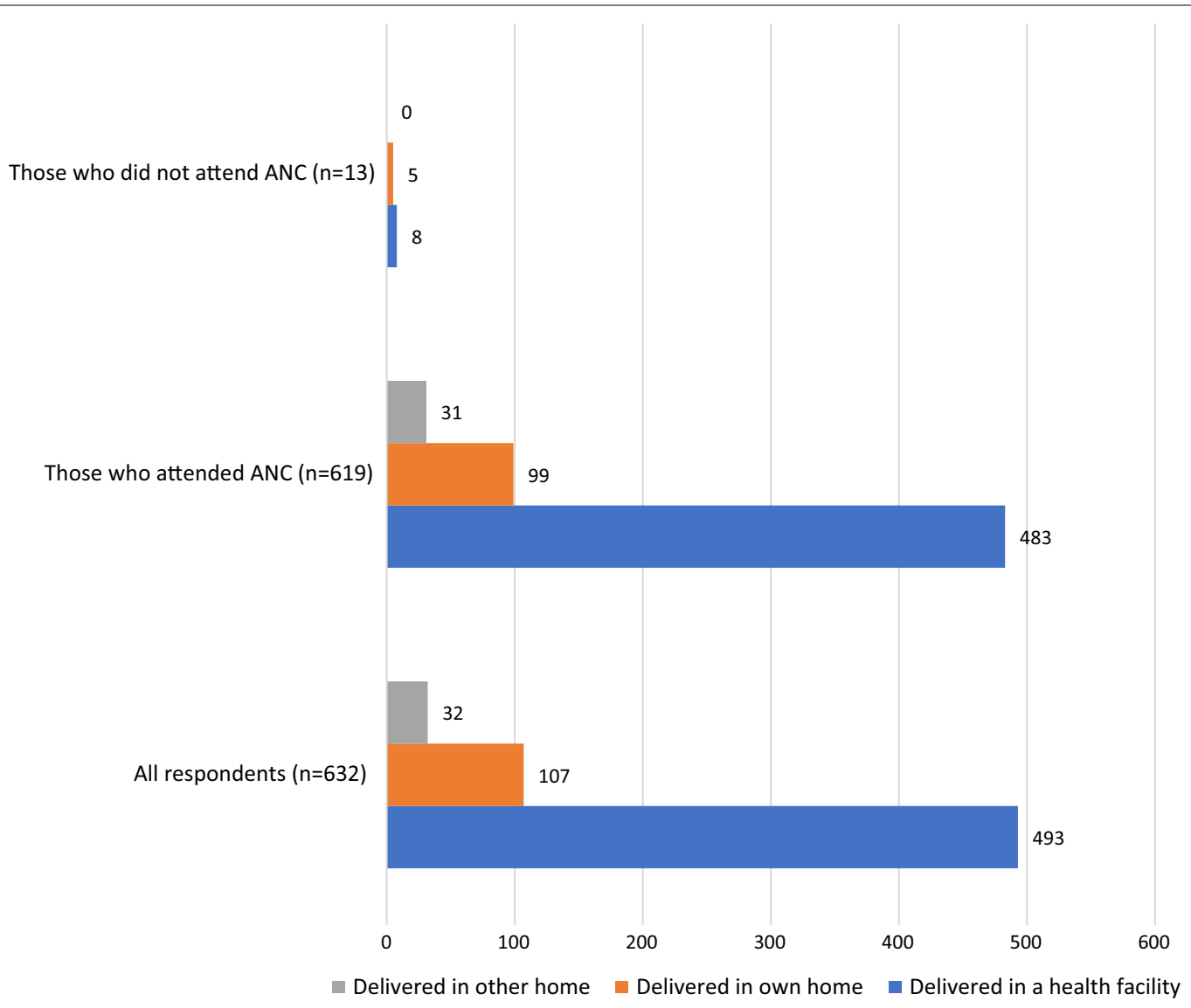

Fig. 1 Respondents place of delivery according to status of ANC attendance 
Table 2 Factors associated with facility-based delivery among women of reproductive age from the Digo community residing in Kwale, Kenya (restricting to only those who reported a previous birth, $n=632$ )

\begin{tabular}{|c|c|c|c|c|}
\hline & \multicolumn{2}{|l|}{ Univariate } & \multicolumn{2}{|l|}{ Multivariate $^{\mathrm{a}}$} \\
\hline & OR $(95 \% \mathrm{Cl})$ & P-value & OR $(95 \% \mathrm{Cl})$ & P-value \\
\hline \multicolumn{5}{|l|}{ Respondent's age (years) } \\
\hline$<30$ & Reference & & & \\
\hline$\geq 30$ & $0.8(0.5-1.2)$ & 0.217 & & \\
\hline \multicolumn{5}{|l|}{ Husband/partner's age (years) } \\
\hline$<40$ & Reference & & & \\
\hline$\geq 40$ & $0.5(0.3-0.9)$ & 0.013 & $0.7(0.4-1.3)$ & 0.262 \\
\hline \multicolumn{5}{|c|}{ Age started living with husband/partner (years) } \\
\hline$<20$ & Reference & & & \\
\hline$\geq 20$ & $1.1(0.7-2.4)$ & 0.360 & & \\
\hline \multicolumn{5}{|l|}{ School attendance (respondent) } \\
\hline Never attended school & Reference & & & \\
\hline Ever attended school & $2.0(1.2-3.2)$ & 0.004 & $1.9(1.1-3.3)$ & 0.030 \\
\hline \multicolumn{5}{|l|}{ Years of education (respondent) } \\
\hline$<8$ years & Reference & & & \\
\hline$\geq 8$ years & $1.4(1.0-2.1)$ & 0.072 & & \\
\hline \multicolumn{5}{|c|}{ School attendance (husband/partner) } \\
\hline Never attended school & Reference & & & \\
\hline Ever attended school & $1.3(0.7-2.4)$ & 0.360 & & \\
\hline \multicolumn{5}{|l|}{ ANC attendance } \\
\hline Did not attend ANC & Reference & & & \\
\hline Attended ANC & $2.4(0.7-8.7)$ & 0.175 & & \\
\hline \multicolumn{5}{|l|}{ Ideal ANC attendance ${ }^{b}$} \\
\hline No & Reference & & & \\
\hline Yes & $2.3(1.4-3.7)$ & 0.001 & $2.0(1.0-3.8)$ & 0.040 \\
\hline \multicolumn{5}{|l|}{ Marital status } \\
\hline Not in a marital union & Reference & & & \\
\hline In a marital union & $1.4(0.9-2.4)$ & 0.159 & & \\
\hline Not living with marital partner & Reference & & & \\
\hline Living with marital partner & $1.3(0.8-2.1)$ & 0.376 & & \\
\hline Monogamous & Reference & & & \\
\hline Polygamous & $0.6(0.3-0.9)$ & 0.024 & $0.7(0.4-1.3)$ & 0.228 \\
\hline \multicolumn{5}{|l|}{ Pregnancy intention } \\
\hline Didn't want to get pregnant & Reference & & & \\
\hline Wanted to get pregnant & $1.5(1.0-2.2)$ & 0.040 & $1.5(0.9-2.6)$ & 0.106 \\
\hline \multicolumn{5}{|c|}{ Gainfully employed past 12 months } \\
\hline No & Reference & & & \\
\hline Yes & $0.6(0.4-1.2)$ & 0.138 & & \\
\hline
\end{tabular}

a Adjusted for husband/partner's age, education (both respondent's and husband/partner's), ideal ANC attendance, being in a polygamous relationship and pregnancy intention

b Constitutes having attended $\geq 4$ ANC visits, having received information on pregnancy danger signs, having received $\geq 3$ tetanus toxoid vaccinations, having received anti-malarial, anti-helminthic and hematinic supplementation

behind high rates of ANC attendance [10-12]. This is despite the fact that facility-based delivery has been associated with favourable maternal and neonatal outcomes. Different studies have revealed various barriers associated with this disparity including traditional and familial influences, high costs, low perceived quality of care and fear of discrimination during facilitybased delivery [3, 13-16]. Women who have otherwise attended ANC well have reported fearing poor quality 
of services during childbirth which makes them prefer a home delivery [17-19].

Further, our findings show that the proportion of facility-based deliveries has increased over time, which is consistent with several other studies in this setting $[20,21]$. This is likely related to the government of Kenya's policy on free maternity services that was rolled out in June 2013. This policy has been credited with increasing the absolute numbers of pregnant women who deliver in health facilities [22]. However, our study showed a disparity between ANC attendance and facility-based delivery. The number of women who ultimately delivered in a health facility was lower than those who reported attending ANC in the same pregnancy.

The antenatal period offers a unique opportunity to promote healthy behaviors and practices. It serves as an ideal point during a woman's pregnancy for discussing the choice of place of delivery [23, 24]. It also offers an opportunity to influence the decision-making process and respond to complaints and concerns $[25,26]$. Our findings show that the likelihood of a facility-based delivery in this setting was more than twice as likely if a woman had received ideal ANC services during her pregnancy. In order to improve maternal and neonatal outcomes therefore, it is important to leverage demand-side factors that harness missed opportunities during ANC so as to promote uptake of facility-based delivery.

Studies have shown that educated girls and women are able to make better-informed health-related decisions $[27,28]$. Successful completion of primary education among African girls has also been strongly associated with better SRH outcomes [29]. Our findings show that women who had ever attended school in this setting were twice as likely to have delivered in a health facility compared to those who had never attended school. Programs targeting to improve $\mathrm{MCH}$ outcomes should incorporate interventions encouraging educational attainment as well as promoting adult literacy training.

Finally, we have previously shown that pregnancy intention was associated with uptake of contraceptive services. The current findings reinforce the fact that women who plan if and when to get pregnant are more likely to deliver in a health facility. Previous studies have had mixed results regarding the role of pregnancy intendedness on influencing skilled attendance at birth especially after accounting for socioeconomic and demographic factors [30]. What is clear however, is that pregnancy intendedness could influence the quality of ANC services sought for. As our findings reveal, this could ultimately affect choice of place of delivery.

\section{Limitations}

These findings need to be interpreted within the context of several limitations:

- Lack of data on some known correlates of facility delivery including household income as well as distance to health facility/time required to reach health facility.

- Cross-sectional study design leading to inability to infer causality.

- Self-reported responses may be subject to reporting bias.

\section{Additional file}

Additional file 1. Sexual and reproductive health questionnaire. Questionnaire administered to all respondents within their households.

\section{Abbreviations}

ANC: antenatal care; $\mathrm{Cl}$ : confidence interval; IQR: interquartile range; $\mathrm{MCH}$ : maternal child health; MNM: Mama Na Mtoto Project; MOMI: Missed Opportunities in Maternal and Infant Health Project; OR: odds ratio; SRH: sexual and reproductive health; WRA: women of reproductive age.

\section{Authors' contributions}

VM, AL and PG conceptualized the idea for this study. VM and HEB supervised field data collection activities. VM analyzed the data and prepared the first draft of the manuscript. HEB, AL, MT and PG assisted with interpreting the data. AL, MT and PG revised the manuscript for proper intellectual content. All authors read and approved the final manuscript.

\section{Author details}

${ }^{1}$ International Centre for Reproductive Health, P.O. Box 91109-80103,

Mombasa, Kenya. ${ }^{2}$ University of Ghent, Ghent, Belgium. ${ }^{3}$ Community Health Department, Aga Khan University, Mombasa, Kenya. ${ }^{4}$ Department of Health, County Government of Kwale, Kwale, Kenya. ${ }^{5}$ University of Nairobi, Nairobi, Kenya.

\section{Acknowledgements}

The authors would like to acknowledge all the study respondents, the Kwale county and sub-county administration including the health management teams as well as the general Digo community residing in the study location for opening up their villages and homes to our team of investigators. Finally, we would also like to acknowledge the European Commission for providing the necessary resources to conduct this study.

\section{Competing interests}

The authors declare that they have no competing interests.

\section{Availability of data and materials}

The datasets used and/or analyzed during the current study are available from the corresponding author on reasonable request.

\section{Consent for publication}

Not applicable.

\section{Ethics approval and consent to participate}

Ethical approval for the study was obtained from the Research Ethics Committee of the Aga Khan University, Nairobi (2014/REC-51) and the Ethics

Review Committee of the University of Nairobi and Kenyatta National Hospital (P502/08/2014). We also obtained a research permit from the National Commission for Science, Technology and Innovation (\#4703) to facilitate the 
conduct of research activities in the community. All participants provided written informed consent.

\section{Funding}

Funding for this study was provided through the Missed Opportunities in Maternal and Infant health (MOMI) project (www.momiproject.eu) funded by the European Commission Seventh Framework Programme (Grant Agreement \#265448) and the Mama Na Mtoto II (MNM II) project funded by the Delegation of the European Commission in Kenya (Contract \# DClNSAPVD/2011/276-298). The funders played no role in either the design of the study and collection, analysis, and interpretation of data and in preparation of this manuscript

\section{Publisher's Note}

Springer Nature remains neutral with regard to jurisdictional claims in published maps and institutional affiliations.

Received: 19 July 2018 Accepted: 3 October 2018 Published online: 10 October 2018

\section{References}

1. Schwartz DA. Maternal mortality: risk factors, anthropological perspectives, prevalence in developing countries and preventive strategies for pregnancy-related deaths, vol. xiv. New York: Nova Publishers; 2015. p. 471.

2. Gates M, Warren K, Grant A, Hope Through Healing Hands. The mother \& child project: raising our voices for health and hope. Grand Rapids: Zondervan; 2015. p. 239.

3. Bohren MA, Hunter EC, Munthe-Kaas HM, Souza JP, Vogel JP, Gulmezoglu AM. Facilitators and barriers to facility-based delivery in low- and middleincome countries: a qualitative evidence synthesis. Reprod Health. 2014;11(1):71

4. Duysburgh E, Kerstens B, Kouanda S, Kabore CP, Belemsaga Yugbare D, Gichangi P, et al. Opportunities to improve postpartum care for mothers and infants: design of context-specific packages of postpartum interventions in rural districts in four sub-Saharan African countries. BMC Pregnancy Childbirth. 2015;15:131

5. Aga Khan Health Service. Mama na Mtoto II baseline household survey report. Msambweni District, 2012. http://www.akdn.org/project/mamana-mtoto. Accessed 27 Mar 2017.

6. Mochache V, Lakhani A, El-Busaidy H, Temmerman M, Gichangi P. Pattern and determinants of contraceptive usage among women of reproductive age from the Digo community residing in Kwale, Kenya: results from a cross-sectional household survey. BMC Womens Health. 2018:18(1):10.

7. Djellouli N, Mann S, Nambiar B, Meireles P, Miranda D, Barros H, et al. Improving postpartum care delivery and uptake by implementing context-specific interventions in four countries in Africa: a realist evaluation of the missed opportunities in maternal and infant health (MOMI) project. BMJ Glob Health. 2017;2(4):e000408.

8. Kitui J, Lewis S, Davey G. Factors influencing place of delivery for women in Kenya: an analysis of the Kenya demographic and health survey, 2008/2009. BMC Pregnancy Childbirth. 2013;13:40

9. Mwangi W, Gachuno O, Desai M, Obor D, Were V, Odhiambo F, et al. Uptake of skilled attendance along the continuum of care in rural Western Kenya: selected analysis from Global Health initiative survey-2012. BMC Pregnancy Childbirth. 2018;18(1):175.

10. Boah M, Mahama AB, Ayamga EA. They receive antenatal care in health facilities, yet do not deliver there: predictors of health facility delivery by women in rural Ghana. BMC Pregnancy Childbirth. 2018;18(1):125.

11. Anastasi $E$, Borchert M, Campbell OM, Sondorp E, Kaducu F, Hill O, et al. Losing women along the path to safe motherhood: why is there such a gap between women's use of antenatal care and skilled birth attendance? A mixed methods study in northern Uganda. BMC Pregnancy Childbirth. 2015:15:287.
12. Choe SA, Kim J, Kim S, Park Y, Kullaya SM, Kim CY, Do antenatal care visits always contribute to facility-based delivery in Tanzania? A study of repeated cross-sectional data. Health Policy Plan. 2016;31(3):277-84.

13. Montagu D, Sudhinaraset M, Diamond-Smith N, Campbell O, Gabrysch $S$, Freedman $L$, et al. Where women go to deliver: understanding the changing landscape of childbirth in Africa and Asia. Health Policy Plan. 2017;32(8):1146-52.

14. Diamond-Smith N, Sudhinaraset M, Montagu D. Clinical and perceived quality of care for maternal, neonatal and antenatal care in Kenya and Namibia: the service provision assessment. Reprod Health. 2016;13(1):92.

15. Kinuthia J, Kohler P, Okanda J, Otieno G, Odhiambo F, John-Stewart G. A community-based assessment of correlates of facility delivery among HIV-infected women in western Kenya. BMC Pregnancy Childbirth. 2015:15:46

16. Kruk ME, Kujawski S, Mbaruku G, Ramsey K, Moyo W, Freedman LP. Disrespectful and abusive treatment during facility delivery in Tanzania: a facility and community survey. Health Policy Plan. 2018;33(1):e26-33.

17. Creanga AA, Odhiambo GA, Odera B, Odhiambo FO, Desai M, Goodwin $M$, et al. Pregnant women's intentions and subsequent behaviors regarding maternal and neonatal service utilization: results from a cohort study in Nyanza Province, Kenya. PLoS ONE. 2016;11(9):e0162017.

18. Gitobu CM, Gichangi PB, Mwanda WO. Satisfaction with delivery services offered under the free maternal healthcare policy in Kenyan public health facilities. J Environ Public Health. 2018;2018:4902864.

19. Virgo S, Gon G, Cavallaro FL, Graham W, Woodd S. Who delivers where? The effect of obstetric risk on facility delivery in East Africa. Trop Med Int Health. 2017:22(9):1081-98.

20. Chea SK, Mwangi TW, Ndirangu KK, Abdullahi OA, Munywoki PK, Abubakar A, et al. Prevalence and correlates of home delivery amongst HIVinfected women attending care at a rural public health facility in Coastal Kenya. PLoS ONE. 2018;13(3):e0194028.

21. Moindi RO, Ngari MM, Nyambati VC, Mbakaya C. Why mothers still deliver at home: understanding factors associated with home deliveries and cultural practices in rural coastal Kenya, a cross-section study. BMC Public Health. 2016;16:114.

22. Calhoun LM, Speizer IS, Guilkey D, Bukusi E. The effect of the removal of user fees for delivery at public health facilities on institutional delivery in urban Kenya. Matern Child Health J. 2018;22(3):409-18.

23. Exavery A, Kante AM, Njozi M, Tani K, Doctor HV, Hingora A, et al. Access to institutional delivery care and reasons for home delivery in three districts of Tanzania. Int J Equity Health. 2014;13:48

24. Nyongesa C, Xu X, Hall JJ, Macharia WM, Yego F, Hall B. Factors influencing choice of skilled birth attendance at ANC: evidence from the Kenya demographic health survey. BMC Pregnancy Childbirth. 2018;18(1):88.

25. Arunda M, Emmelin A, Asamoah BO. Effectiveness of antenatal care services in reducing neonatal mortality in Kenya: analysis of national survey data. Glob Health Action. 2017:10(1):1328796.

26. Berhan Y, Berhan A. Antenatal care as a means of increasing birth in the health facility and reducing maternal mortality: a systematic review. Ethiop J Health Sci. 2014;24(Suppl):93-104

27. Berhan Y, Berhan A. A meta-analysis of socio-demographic factors predicting birth in health facility. Ethiop J Health Sci. 2014;24(Suppl):81-92.

28. Gitimu A, Herr C, Oruko H, Karijo E, Gichuki R Ofware P, et al. Determinants of use of skilled birth attendant at delivery in Makueni, Kenya: a cross sectional study. BMC Pregnancy Childbirth. 2015;15:9.

29. Ziraba A, Orindi B, Muuo S, Floyd S, Birdthistle IJ, Mumah J, et al. Understanding HIV risks among adolescent girls and young women in informal settlements of Nairobi, Kenya: lessons for DREAMS. PLOS ONE. 2018;13(5):e0197479.

30. Marston C, Cleland J. Do unintended pregnancies carried to term lead to adverse outcomes for mother and child? An assessment in five developing countries. Popul Stud (Camb). 2003:57(1):77-93. 